\title{
The relationship between the spiritual attitude of the family caregivers of older patients with stroke and their burden
}

This article was published in the following Dove Press journal:

Clinical Interventions in Aging

I March 2017

Number of times this article has been viewed

\author{
Razieh Torabi Chafjiri' \\ Nasrin Navabi ${ }^{2}$ \\ Abbas Shamsalinia ${ }^{2}$ \\ Fatemeh Ghaffari ${ }^{2}$ \\ 'Gilan University of Medical Sciences, \\ Rudsar Shahid Ansari Hospital, \\ Rudsar, Gilan, Iran; ${ }^{2}$ Ramsar Nursing \\ Care Research Center, School \\ of Nursing and Midwifery, Babol \\ University of Medical Sciences, \\ Babol, Mazandaran, Iran
}

Introduction: Stroke is a chronic condition that necessitates multidimensional and overwhelming care. The caregivers of stroke patients are faced with various stressors that can threaten different aspects of their health, especially their mental health. Spiritual attitude and being spiritually oriented contribute significantly to mental health and can be used as a strategy for adapting to the stressful events that are part of the role of caregiving. This study was therefore conducted to investigate the relationship between the spiritual attitude of the family caregivers of older patients with stroke and their burden.

Methods: This descriptive cross-sectional study was conducted in 2016. The study population consisted of all the family caregivers of older patients with stroke presenting to health care centers and nursing service companies of Gilan Province in Iran. The participants were selected through convenience sampling and consisted of 407 participants. Data were collected using the Spiritual Attitude Scale and the Caregiver Burden Inventory and were then analyzed in SPSS-18 using Pearson's correlation coefficient at a significance level of 0.05 .

Results: The results showed that $88.9 \%$ of the caregivers were females. The mean age of the participants was $38.3 \pm 8.8$ years. The duration of caregiving was $<5$ years in $84.4 \%$ of the participants, while its mean was $4.2 \pm 2.5$ years. The mean score of spiritual attitude was $108.77 \pm 6.20$. The majority of the participants (49.3\%) had moderate and relatively favorable spiritual attitude (a score of 72-120), 27.8\% had high or favorable spiritual attitude; $8.7 \%$ had mild burden, $54.4 \%$ had moderate burden and $37 \%$ had favorable burden. The mean score of burden was $28 \pm 12.75$. A statistically significant positive relationship was observed in this study between the mean score of spiritual attitude and the total score of burden in all its dimensions, namely, time dependence, as well as the developmental, physical, social and emotional dimensions.

Conclusion: Providing strategies for improving spirituality, such as teaching spiritual selfcare, can improve their burden. Given that such strategies are psychologically approved and pose no side effects, they can be used as an effective, low-cost and risk-free approach for all caregivers, so that they can acquire the necessary spiritual support for overcoming the stress caused by caring for family members through the reinforcement of their spiritual beliefs in the ultimate effort to provide effective care to older patients while maintaining their own health and quality of life.

Keywords: spiritual attitude, burden, family caregivers, older patients, stroke

\section{Introduction}

Stroke is a common chronic condition developed in old age, which can be followed by multiple physical and social restrictions on older patients and impair their functioning in different aspects of their life. ${ }^{1}$ Studies show that stroke is the third leading cause 
of death due to disability in the US and industrial European countries. On average, one stroke occurs every 45 seconds across the world and one individual dies every 3 minutes due to stroke. ${ }^{2,3}$

Stroke is a condition that has great effects on the patient as well as on his/her family, whose members play the supportive role of caregivers over the course of the patient's disease. About $80 \%$ of stroke patients are dependent on their family for their daily activities and the family is thus faced with the great burden of caring for the patient. ${ }^{4}$ Given that poststroke changes are severe, the caregiver should adapt to the changes caused by stroke and shift his/her lifestyle toward one of caregiving; to add to the challenge, the caregiver finds himself/ herself in the position of caregiver with no prior notice or preparation. As a result, caregivers experience poor quality of life and are at risk for developing different physical and mental diseases. ${ }^{4,5}$

Most caregivers experience burnout, loneliness, depression, as well as diminished physical and mental health, and their burnout reduces their quality of care. ${ }^{4}$ The job of caregiving is associated with other responsibilities, such as family- and job-related roles, housekeeping and the fear of not being recognized in the society as a caregiver, and this can lead to reduced self-efficacy and increased risk of developing chronic physical and mental disorders. The caregivers of older patients with chronic conditions such as stroke are at risk of developing health problems themselves due to the lack of enough rest, as well as disrupted sleep, chronic fatigue, economic difficulties and depression. ${ }^{5}$ Many studies have presented strategies for reducing these problems by way of increasing the caregivers' adaptation and reducing burden. ${ }^{6-9}$ With respect to the burden imposed on the caregivers of older patients with stroke, identifying the variables that affect their adaptation can help offer effective strategies for improving caregivers' health and quality of life. ${ }^{10-13}$ One of the strategies proposed for increasing adaptation in caregivers is for them to become more spiritually oriented. The increasing tendency toward spirituality across the world has led to greater research interest in using this parameter as a serious strategy for solving the discussed problems. ${ }^{8,9}$ This study was conducted to determine the relationship between the spiritual attitude of the family caregivers of older patients with stroke and their level of burden.

\section{Methods}

\section{Study design}

The present descriptive cross-sectional study was conducted in 2016.

\section{Study participants}

The study population consisted of all the family caregivers of older patients with stroke presenting to health care centers and nursing service companies of Gilan Province in Iran. Morgan Table was used to calculate the sample size, ie, 397 participants. However, in order to distribute the sample size appropriately, 407 participants were considered. The study inclusion criteria for the caregivers included being a Muslim, not being the caregiver of any other patient aside from the older patient with stroke, being responsible for the full-time and complete care of the patient, being a relative of the patient, not being paid for his/her care duties, having spent at least 6 months caring for the patient and consenting to participation in the study. ${ }^{4}$ The necessary information about the study was orally presented to the participants. Moreover, participation in the study was both voluntary and anonymous. Informed consent was obtained from all study participants.

\section{Data collection}

Data were collected through the following instruments:

1. A demographic data questionnaire with items on age, gender, level of education, occupation, marital status, place of residence and the duration of caregiving.

2. The Spiritual Attitude Scale, with items in three dimensions, namely, cognitive, emotional and behavioral. ${ }^{14}$ The test-retest reliability of this scale was evaluated within a 4-week interval and was confirmed with a correlation coefficient of 0.71 . The internal consistency of the scale was also confirmed with a Cronbach's alpha value of 0.93 for the entire test. The internal consistency of the items within each component was also confirmed. ${ }^{8}$ The scores obtained ranged from a maximum of 152 to a minimum of 20. Obtaining a score of 109-152 was taken to indicate high and favorable attitude, a score of 65-108 moderate and relatively favorable attitude and a score of 20-64 low and unfavorable attitude. ${ }^{8,9}$

3. The Caregiver Burden Inventory, developed by Novak and Guest ${ }^{10}$ with five subscales, including Time-Dependence Burden, Developmental Burden, Physical Burden, Social Burden and Emotional Burden. The total score obtained on this inventory ranged from 24 to 120 . Given the mean and standard deviation of the total burden scores, a score of 24-39 was taken to signify mild burden, a score of 40-71 moderate burden and a score of 72-120 favorable burden. ${ }^{10}$ This inventory has acceptable reliability and validity, and the internal consistency of the subscales was calculated as 0.85 for time-dependence burden, 0.85 
for developmental burden, 0.86 for physical burden, 0.73 for social burden and 0.77 for emotional burden. ${ }^{11,12}$ The test-retest reliability of the inventory was also confirmed with $r=0.89$. All the questionnaires were completed by the caregivers themselves. All the questionnaires were fully completed and there was no attrition sampling.

\section{Data analysis}

In this study, the normal distribution of the data was determined using the Kolmogorov-Smirnov test. The test result showed that the participants' scores were normally distributed. Descriptive statistics were used to describe the study population, including count, percentage, mean and standard deviation. Moreover, Pearson's correlation analysis was used to show any significant correlation between spiritual attitude and burden. Chi-square tests, independent-samples $t$-tests and Linear regression was used to show any significant correlation between burden and demographic characteristics. Data were analyzed using SPSS 18.0. software (SPSS, Inc., Chicago, IL, USA).

\section{Ethical considerations}

The study protocol of this research was approved by the Babol University of Medical Sciences (No UBABOL. REC.2016.157). All the participants were aware of the research aims. They were assured about the secrecy of their information. They were also informed about the right of discontinuing the process, although none of them left the study.

\section{Results}

The results showed that $362(88.9 \%)$ of the caregivers were females. The mean age of the participants was $38.3 \pm 8.8$ years. In terms of marital status, $54.5 \%$ of the caregivers were married. In terms of occupation, $65.6 \%$ were housewives; in terms of the level of education, $96.6 \%$ had a high school education or less. The majority of the caregivers lived at their own home (67.3\%). The duration of caregiving was $<5$ years in $84.4 \%$ of the participants, while its mean was $4.2 \pm 2.5$ years. The results showed a statistically significant relationship between caregiving burden and the variables of age, gender, occupation, marital status, place of residence and the duration of caregiving; however, no significant relationships were observed between the level of education and this burden (Table 1).

The mean score of spiritual attitude was $108.77 \pm 6.20$ and most of the participants (49.3\%) had moderate and relatively favorable spiritual attitude, while $27.8 \%$ had high
Table I The relationship between caregiving burden and the demographic characteristics of the participants

\begin{tabular}{|c|c|c|c|}
\hline Characteristic & $\mathbf{N}$ & Percentage & $P$-value \\
\hline \multicolumn{4}{|l|}{ Gender } \\
\hline Male & 45 & II.I & $<0.001$ \\
\hline Female & 362 & 88.9 & - \\
\hline \multicolumn{4}{|l|}{ Age, years } \\
\hline$<20$ & 10 & 2.5 & $<0.01$ \\
\hline $20-40$ & 185 & 70 & - \\
\hline$>40$ & 122 & 27.5 & - \\
\hline \multicolumn{4}{|l|}{ Level of education } \\
\hline High school education or less & 393 & 96.6 & 0.23 \\
\hline University education & 14 & 3.4 & - \\
\hline \multicolumn{4}{|l|}{ Marital status } \\
\hline Married & 221 & 54.3 & $<0.01$ \\
\hline Single & 186 & 45.7 & - \\
\hline \multicolumn{4}{|l|}{ Place of residence } \\
\hline Own home & 274 & 67.3 & $<0.001$ \\
\hline Parents' home & 133 & 2.7 & - \\
\hline \multicolumn{4}{|l|}{ Duration of caregiving, years } \\
\hline$<5$ & 336 & 82.6 & $<0.001$ \\
\hline $6-10$ & 60 & 14.7 & - \\
\hline$>10$ & 11 & 2.7 & - \\
\hline \multicolumn{4}{|l|}{ Occupation } \\
\hline Self-employed & 54 & 13.2 & $<0.01$ \\
\hline Housewife & 267 & 65.6 & - \\
\hline Employee & 86 & 21.1 & - \\
\hline
\end{tabular}

or favorable spiritual attitude. A total of $8.7 \%$ of the participants had mild burden, $54.4 \%$ had moderate burden and $37 \%$ had favorable burden. The mean score of burden was $28 \pm 12.75$ (Table 2).

A statistically significant positive relationship was observed in this study between the mean score of spiritual attitude and the total score of burden in all its dimensions, namely, time dependence, as well as the developmental, physical, social and emotional dimensions $(P<0.05$; Table 3$)$.

The results showed that $24 \%$ of the burden of the family caregivers of older patients with stroke can be predicted by spiritual attitude (Table 4).

Table 2 The descriptive statistics

\begin{tabular}{lcccl}
\hline Burden & Minimum & Maximum & Mean & $\begin{array}{l}\text { Standard } \\
\text { deviation }\end{array}$ \\
\hline Total score of spiritual & 99.00 & 152.00 & 108.77 & 6.20 \\
attitude & & & & \\
Time dependence burden & 7.00 & 19.00 & 12.17 & 3.33 \\
Developmental burden & 2.00 & 11.00 & 5.38 & 2.08 \\
Physical burden & 2.00 & 12.00 & 4.13 & 2.47 \\
Social burden & 1.00 & 20.00 & 3.89 & 4.65 \\
Emotional burden & 1.00 & 10.00 & 2.14 & 2.37 \\
Total score of burden & 18.00 & 69.00 & 28.00 & 12.75 \\
\hline
\end{tabular}


Table 3 The correlation coefficients for relationship between burden and spiritual attitude

\begin{tabular}{lllll}
\hline Variable & & Index & & \\
\cline { 1 - 1 } Predictive & & Criterion & $\begin{array}{c}\text { Correlation } \\
\text { coefficient }\end{array}$ & Significance \\
\hline Spiritual & & Time dependence & 0.38 & 0.001 \\
attitude & burden & & \\
& Developmental burden & 0.43 & 0.004 \\
& Physical burden & 0.53 & 0.009 \\
& Social burden & 0.35 & 0.004 \\
& Emotional burden & 0.51 & 0.001 \\
& Total score of burden & 0.46 & 0.001 \\
\hline
\end{tabular}

\section{Discussion}

This study showed that caregiving burden increases with age. With age, the caregiver enters middle age himself/ herself and becomes engaged with issues such as retirement, children's marriage and problems related to the onset of old age; nevertheless, he/she comes to better understand the older adult's conditions and needs and therefore builds up higher tolerance for providing care to the older adult. ${ }^{13}$ Moreover, young caregivers may have greater roles within the family or society in addition to their caregiving role and, therefore, experience greater caregiving pressure, with the majority having to give up their social and professional life for their caregiving role. In contrast, some studies showed that caregiving burden increases with the caregiver's age, and the greater vulnerability that comes with age ends up making him/her more susceptible to the negative effects of caregiving. The ability and efficacy of the caregiver decrease with age, to the degree that he/she may himself/herself require help from others. He/she may also be faced with new conditions and difficulties in life and may not be able to perform well in her/his role as caregiver. ${ }^{14-16}$

This study also found female caregivers to have higher burden than male caregivers, which may be due to the Iranian tradition of more frequently placing females in caregiving roles, as a result of which females generally feel more responsible toward such tasks. The burden of female caregivers is higher than their male peers because of the greater emotional

Table 4 Predicting burden by the spiritual attitude of the family caregivers of older patients with stroke

\begin{tabular}{|c|c|c|c|c|c|c|c|}
\hline \multirow{2}{*}{\multicolumn{4}{|c|}{ Predictive variable }} & \multicolumn{4}{|c|}{ Index } \\
\hline & & & & \multicolumn{4}{|c|}{ Coefficient } \\
\hline$R$ & RS & $F$ significance & SE & B & $\beta$ & $t$ & Significance \\
\hline- & - & - & 11.45 & 42.71 & - & 3.062 & 0.001 \\
\hline 0.49 & 0.24 & $\mid 4.752$ & 0.103 & $0.46 I$ & 0.455 & 4.079 & 0.003 \\
\hline
\end{tabular}

Abbreviations: $\mathrm{RS}$, residual sum; $\mathrm{SE}$, standard error. attachment between females and their older parents. In a relevant study in Brazil, which is another society that often gives the caregiving role to females, the majority of the caretakers of parents and children were females, while the males worked outside the home and earned a living. ${ }^{17}$ In Europe, more than $80 \%$ of the caregiving roles are occupied by informal caregivers and $75 \%$ of the roles are performed by females. ${ }^{15}$

Studies confirm the effect of gender differences on the burnout and pressure caused by caregiving, as females experience greater stress and mental pressure than males. Females experience greater burnout and fatigue because they are often the primary caregivers and have to attend to their children and social commitments as well. ${ }^{6,16-18}$ A significant relationship was observed in the current study between employment status and caregiving burden, which can be explained by noting that most of the caregivers were housewives. Being employed outside the house confronts the caregiver with fatigue and several social and personal problems. Caregivers who seek to create a balance between their job and other activities, such as recreation, family time and studying, may find it difficult to concentrate on the positive aspects of their caregiving role and often show more negative reactions in their role as caregiver of older adults. This group often has limited time for taking care of older adults. ${ }^{19}$ An older adult's caregiver who has a job may experience impaired social roles and activities, as well as greater stress. The mental and physical health of caregivers is thus also affected by the older adult's health, and their social life also becomes limited under the influence of their caregiving role. ${ }^{20,21}$ In a study conducted by Grunfeld et al, ${ }^{19}$ caregivers experienced even higher anxiety and depression than the patients (69\%), those caregivers who were employed also experienced personal problems in their workplace and $77 \%$ of them lost their jobs at severe stages of their older patient's disease due to their extreme sense of responsibility. In a study by Wadhwa et al, ${ }^{21}$ half of the caregivers were employed and $25 \%$ ultimately had to change their jobs, in addition to experiencing greater personal and social problems.

The results of this study also revealed a higher burden on the married caregivers than on single ones, perhaps owing to the former's better adaptability resulting from the greater responsibilities, problem-solving ability and interpersonal conflict resolution that come with marriage. ${ }^{17}$

This study found that live-in caregivers have a lower burden, perhaps because live-out caregivers can spend a few hours a day away from the older adult's problems and have more time to spend on their own daily activities. ${ }^{4}$ 
The results also revealed that the duration of the caregiving role has a significant effect on the caregivers' burden, because the longer was this duration, the less became the family caregiver's burden. Due to the constant pressure of caregiving, as well as the older adults' physical dependence on them as well as inability to perform their daily activities by themselves, caregivers are exposed to a great amount of stress and gradually lose their burden. In a study by Anderson et al, ${ }^{22}$ long-term caregivers of older patients with stroke experienced greater emotional tension manifested in the form of anxiety, anger and depression. In another study, Suh et $\mathrm{a}^{23}$ showed that caregivers' burden increases as the duration of caring for the older adult with stroke increases because taking care of patients at home is a complex and multidimensional task that may consume the individual physically and psychologically. The caregivers of (older) patients with chronic conditions, including stroke, experience many problems and have to constantly meet both their own and their patient's needs and therefore end up experiencing a greater caregiving burden, which impairs their performance of their caregiving role. ${ }^{5,13}$

In one study, Chang et $\mathrm{al}^{24}$ showed that caregivers who spend more time taking care of their patient experience greater caregiving pressure and have lower mental health. In a study by Hydary and Mokhtari Hesari, ${ }^{20}$ the family caregivers of patients with cancer who had been taking care of their patients for 6 months or more suffered from various mental problems themselves.

In line with the results of the current study, Malakouti et al ${ }^{25}$ also found that increased caregiving pressure is associated with various outcomes, such as social isolation, disrupted family relationships, inadequate patient care and ultimately letting go of the patient.

In the current study, the caregivers of older patients with stroke were spiritually inclined, probably owing to the cultural and religious background of Iran and the religious beliefs of its people. Family caregivers often have a religious approach to the difficulties of life according to their cultural and belief system and regard disease as a Divine trial and a manifestation of His wisdom. ${ }^{9,26}$

The results of this study showed a significant positive relationship between spiritual attitude and caregiving burden in the family caregivers of older patients with stroke. Some researchers have shown that religion and spirituality are significant resources in the adaptation to stressful life events. ${ }^{26,27}$ In fact, spirituality affects not only one's state of mind and mental health, but it also improves physical health and increases the ability to deal with crises. In times of crisis, religion offers a refuge from the problems and disadvantages of life. . $^{1426,27}$
Spirituality is a human dimension that is manifested more distinctly in times of crisis and stress and it creates meaningfulness in life and inspires the confrontation of problems. ${ }^{8,28}$ In one study, Tuck ${ }^{29}$ showed that spiritual interventions help improve the quality of life and reduce the response to stress, tension and depression. Spirituality reduces the stress caused by inability and improves the quality of life, increases life span and reduces anxiety, depression and suicidal tendencies. ${ }^{30}$ Some believe that, without spiritual health, the other dimensions of health cannot have their maximum performance and that high quality of life is not attainable without this particular dimension of health. ${ }^{8}$

\section{Conclusion}

This study revealed a lower burden in young, male, employed and live-in caregivers of older patients. Using informal caregivers can help reduce the burden of family caregivers and improve different aspects of their health and give them more time and energy to take care of the older patient. Involving all the members of the family in caregiving, dividing the duties and taking turns to perform the job help improve family caregivers' adaptation to their role. The results showed that one's spiritual attitude plays a significant role in elevating the level of burden and reducing the pressure caused by providing care to older patients with stroke. Presenting strategies that help improve their spirituality, such as teaching spiritual self-care, can help improve their burden caused by the agitations of caregiving.

\section{Study limitations}

Differences in the interpretation of the questionnaire items may have affected the family caregivers' responses, although the researchers sought to clarify any ambiguities for them. Personal, social and family differences may have also affected the responses. Moreover, even though participation in the study was completely voluntary, some of the participants may have responded untruthfully to the questionnaires, which is beyond the researchers' control.

\section{Acknowledgment}

The study protocol of this research was approved by Babol University of Medical Sciences, Ramsar Nursing Care Research Center, No 3672. The authors express their gratitude to all the older adults' family caregivers who helped carry out this study.

\section{Author contributions}

Razieh Torabi Chafjiri participated in data collection. Nasrin Navabi, Abbas Shamsalinia and Dr Fatemeh Ghaffari participated in writing both the manuscript and the proposal. 
All authors contributed toward data analysis, drafting and critically revising the paper and agree to be accountable for all aspects of the work.

\section{Disclosure}

The authors report no conflicts of interest in this work.

\section{References}

1. Paulik E, Bóka F, Kertész A, Balogh S, Nagymajtényi L. Determinants of health-promoting lifestyle behaviour in the rural areas of Hungary. Health Promot Int. 2010;25(3):277-288.

2. Moqaddam AH, Musavi SMRA, Khademizadeh K. Relationship of opium dependency and stroke. Addict Health. 2010;1(1):6-10.

3. Ghayeghran A, Janeshin S, Saberi A, Sohrabnezhad R, Kazemnezhad E. The relationship between opium addiction and ischemic stroke. J Guilan Univ Med Sci. 2016;24(96):42-49.

4. Koohestani H, Baghcheghi N. Burn out in caregivers of patients with stroke and its related factors. Hakim Health Sys Res. 2012;14(4):242-248.

5. Tari Moradi A, Ahadi H. Survey of depression, anxiety and physical health of caregivers to elders with aged and brain stroke. Alborz Univ Med J. 2015;3(4):199-204.

6. Khatiban M, Kheirollahi A, Oshvandi K, Alhani F, Feradmal J. The effect of family-based education on knowledge and self esteem of caregivers of patients with strokes: a randomized controlled trial. J Mazandaran Univ Med Sci. 2014;23(110):243-250.

7. Kim H, Chang M, Rose K, Kim S. Predictors of caregiver burden in caregivers of individuals with dementia. $J$ Adv Nurs. 2012;68(4): 846-855.

8. Rahimi N, Nouhi E, Nakhaee N. Spiritual well-being and attitude toward spirituality and spiritual care in nursing and midwifery students. Iran $J$ Nurs. 2013;26(85):55-65.

9. Ebrahimi H, Ashrafi Z, Eslampanah G, Noruzpur F. Relationship between spiritual well-being and quality of life in hemodialysis patients. J Nurs Midwifery Sci. 2014;1(3):41-48.

10. Novak M, Guest C. Application of a multidimensional caregiver burden inventory. Gerontologist. 1989;29(6):798-803.

11. Muangpaisan W, Praditsuwan R, Assanasen J, et al. Caregiver burden and needs of dementia caregivers in Thailand: a cross-sectional study. J Med Assoc Thai. 2010;93(5):601-607.

12. Bagherbeik Tabrizi L, Navab E, Farokhnezhad Afshar P, Asadi Noghabi AA, Haghani H. Effect of cognitive-behavioral intervention on burden of family caregivers of patients with Alzheimer's disease. J Hayat. 2015;21(1):94-102.

13. Abbasi A, Asayesh H, Rahmani H, Shariati A, Hosseini S, Rouhi Gh. The burden on caregivers from hemodialysis patients and related factors. J Gorgan Univ Med Sci. 2011;8(1):26-33.

14. Shahidi H. Psychometric of attitude to spirituality questionnaire. Ravanshenasi Va Din. 2012;5(3):97-115.
15. Khatti Dizabadi F, Yazdani Cherati J, Eftekhar Ardebili H, Batebi A, Shojaezadeh D. The status of caregiving among informal caregivers of community-dwelling elderly. J Mazandaran Univ Med Sci. 2013; 23(100):31-41.

16. Şenol V, Ünalan D, Soyuer F, Argün M. The relationship between health promoting behaviors and quality of life in nursing home residents in Kayseri. J Geriatr. 2014;2014:8.

17. Pereira RA, Santos EBd, Fhon JRS, Marques S, Rodrigues RAP. Burden on caregivers of elderly victims of cerebrovascular accident. Rev Esc Enferm USP. 2013;47(1):185-192.

18. Khalid T, Kausar R. Depression and quality of life among caregivers of people affected by stroke. Asia Pac Disability Rehabil J. 2008; 19(2):103-110.

19. Grunfeld E, Coyle D, Whelan T, et al. Family caregiver burden: results of a longitudinal study of breast cancer patients and their principal caregivers. Can Med Assoc J. 2004;170(12):1795-1801.

20. Hydary L, Mokhtari Hesari P. Common breast cancer family care giving problems. Iran J Breast Dis. 2015;8(2):7-14.

21. Wadhwa D, Burman D, Swami N, Rodin G, Lo C, Zimmermann C. Quality of life and mental health in caregivers of outpatients with advanced cancer. Psychooncology. 2013;22(2):403-410.

22. Anderson CS, Linto J, Stewart-Wynne EG. A population-based assessment of the impact and burden of caregiving for long-term stroke survivors. Stroke. 1995;26(5):843-849.

23. Suh M, Kim K, Kim I, Cho N, Choi H, Noh S. Caregiver's burden, depression and support as predictors of post-stroke depression: a crosssectional survey. Int J Nurs Stud. 2005;42(6):611-618.

24. Chang H-Y, Chiou C-J, Chen N-S. Impact of mental health and caregiver burden on family caregivers' physical health. Arch Gerontol Geriatr. 2010;50(3):267-271.

25. Malakouti SK, Nouri GAR, Naghavi RM, et al. The burden of caregivers of chronic mental patients and their needs to care and therapeutic services. Hakim. 2003;6(2):1-10.

26. Sadrollahi A, Khalili Z. Spiritual well-being and associated factors among the elderly population in Kashan. J Geriatr Nurs. 2015;1(2): 94-104.

27. Alizadeh M, Fakhrzadeh H, Sharifi F, Zanjari N, Ghassemi S. Comparative study of physical and mental health status of old people in aged groups of 60-64 and 65-69 years old in Tehran metropolitan area. Iran J Diabetes Metab. 2013;13(1):50-61.

28. Mohammadi F, Babaee M [webpage on the Internet]. Effects of participation in support groups on Alzheimer's family caregivers' strain and spiritual wellbeing. Iran J Ageing. 2011;6(1).

29. Tuck I. A critical review of a spirituality intervention. West J Nurs Res. 2012;34(6):712-735.

30. Mandhouj O, Etter J-F, Courvoisier D, Aubin H-J. French-language version of the World Health Organization quality of life spirituality, religiousness and personal beliefs instrument. Health Qual Life Outcomes. 2012;10(1):1.
Clinical Interventions in Aging

\section{Publish your work in this journal}

Clinical Interventions in Aging is an international, peer-reviewed journal focusing on evidence-based reports on the value or lack thereof of treatments intended to prevent or delay the onset of maladaptive correlates of aging in human beings. This journal is indexed on PubMed Central, MedLine,

\section{Dovepress}

CAS, Scopus and the Elsevier Bibliographic databases. The manuscript management system is completely online and includes a very quick and fair peer-review system, which is all easy to use. Visit http://www.dovepress. com/testimonials.php to read real quotes from published authors. 